\title{
THE CLIMATOLOGY OF THE POLAR AEROSOL FROM THE POAM INSTRUMENTS
}

\author{
Helen M. Steele \\ Geography Department \\ California State University Northridge \\ 18111 Nordhoff Street \\ Northridge, California 91330-8249
}

\author{
Jerry D. Lumpe \\ Computational Physics, Inc. \\ 8001 Braddock Road, Suite 210 \\ Springfield, Virginia 22151
}

\author{
Richard M. Bevilacqua \\ Naval Research Laboratory \\ Code 7220 \\ Washington, DC 20375
}

\begin{abstract}
We present a climatology of the high-latitude stratospheric aerosol derived from the multiwavelength extinction data of the POAM (Polar Ozone and Aerosol Measurement) II and III instruments from 1993 to 2003. Stratospheric aerosols north of $54^{\circ} \mathrm{N}$ and south of $63^{\circ} \mathrm{S}$ were continually monitored by POAM II between September 1993 and November 1996. These data clearly show the decay of the volcanic aerosol from the Pinatubo eruption which was still evident when the spacecraft ceased operation at the end of 1996. POAM III was launched into a similar orbit in March 1998 and has monitored the seasonal variation in the aerosol layer since its recovery to background levels. Extinction data from these two instruments at six wavelengths from the ultraviolet to near-infrared are combined through principal component analysis to yield total aerosol surface-area and volume densities. The temporal and spatial evolution of these physical parameters, which can be employed in chemistry and climate models, are presented and analyzed. [Key words: aerosols, stratospheric aerosols, aerosol climatology, POAM.]
\end{abstract}

\section{INTRODUCTION}

Aerosols play a primary role in some of the most important environmental problems concerning our atmosphere today-global warming, ozone depletion and air pollution. Their measurement and characterization are key to understanding and modeling the earth's energy balance, the radiative properties of clouds, the formation of polar stratospheric clouds (important precursors for polar ozone destruction), and air quality. In-situ measurements, which can yield the kind of detailed size distribution and composition information necessary for the study of regional air pollution, are limited both spatially and temporally and cannot provide the 
coverage necessary to address global problems. The global distribution of aerosols is monitored more efficiently through satellite experiments which record either the transmission of solar radiation through the atmosphere, the emission of infrared terrestrial radiation, or the scattering of solar radiation by the earth and its atmosphere. These satellite data are processed through a retrieval algorithm to separate the contributions from the various atmospheric gases and from aerosols. In the case of solar occultation experiments, the resulting aerosol data product is generally a vertical extinction profile at one or more wavelengths. For intercomparison between datasets from different instruments and for incorporation in global chemistry and climate models, these data must be transformed into parameters such as aerosol surface-area and volume density. The study of heterogeneous chemical reactions on aerosol surfaces required to compute ozone depletion rates, and calculations of the radiative properties of aerosols and clouds for climate modeling, both require knowledge of aerosol abundance, composition and size. In the absence of detailed size distribution information, integrated properties of the aerosol layer such as surface-area density $\left(\mu \mathrm{m}^{2} \mathrm{~cm}^{-3}\right)$, and volume or mass density $\left(\mu \mathrm{m}^{3} \mathrm{~cm}^{-3}\right.$ or $\left.\mathrm{g} \mathrm{cm}^{-3}\right)$, are commonly used. These can be derived from the satellite extinction data if some simplifying assumptions are made regarding the size and composition of the aerosols. These assumptions rely on the availability of some in-situ data to provide size range and composition information.

In-situ measurements are most often presented either discretely as counts within a size interval, or analytically, as parameters obtained from fitting experimental data to a prescribed functional form of size distribution. The predominant forms applied to describe stratospheric aerosol size distributions are the uni- and bimodal lognormal functions. Surface areas and volumes are deduced either directly from the discrete data, or from the integration of the fitted analytical size distribution.

Aerosol surface-area and volume density are commonly retrieved from extinction or emission measurements by the use of analytical expressions developed from a combination of in-situ measurements and optical theory. The resulting relationships are then applied globally to infer these macroscopic aerosol properties from satellite extinction data. Such relationships have been established primarily from an extensive suite of in-situ aerosol size distribution measurements made by Deshler et al. over Wyoming and Antarctica (Deshler et al., 1992, 1993, 1994) and applied to satellite data from the CLAES (Cryogenic Limb Array Etalon Spectrometer), ISAMS (Improved Stratospheric and Mesospheric Sounder), and HALOE (Halogen Occultation Experiment) instruments (Grainger et al., 1995; Massie et al., 1996; Hervig and Deshler, 1998). Forward scattering spectrometer probe (FSSP 300) data measured by Dye et al. (1992) and Baumgardner et al. (1992) have also been used to establish similar empirical relationships for polar stratospheric cloud particles (Massie et al., 1998). These methods necessarily assume that global aerosols have the same size and composition characteristics as those from which the relationships originated. A similar method was employed by Bauman et al. (2003a), who used a look-up table to infer area, volume, effective radius and size distribution width from SAGE (Stratospheric Aerosol and Gas Experiment) II and CLAES extinction data by pre-computing the ratios of the extinction at different wavelengths for a range of unimodal lognormal size distributions using Mie theory. This technique was then 
applied to yield a 15-year stratospheric aerosol climatology from SAGE II and CLAES (Bauman et al., 2003b).

An alternative scheme for making the transformation from multiwavelength extinction data to surface-area and volume density is through application of the principal components of the optical extinction function. This technique results in the formulation of a linear relationship between the area or volume density and the aerosol extinction at the various measurement wavelengths, and has been applied to both SAGE and POAM extinction data (Thomason and Poole, 1993; Steele et al., 1999). Application of the principal component methodology to SAGE data has resulted in a 10-year global stratospheric aerosol climatology (Thomason et al., 1997) which shows the history of the aerosol loading, and its evolution through periods of volcanic activity. Here, we employ this technique to yield a climatology of the high-latitude stratospheric aerosol over the past 10 years using data from the POAM II and III satellite instruments.

The POAM II instrument (Glaccum et al., 1996; Lumpe et al., 1997) was launched in September 1993 on the SPOT 3 spacecraft, and functioned for three years until November 1996, taking 14 measurements per day in each hemisphere between 54 and $71^{\circ} \mathrm{N}$, and 63 and $88^{\circ} \mathrm{S}$. Latitudinal progression is slow-only $1-2^{\circ}$ per weekand thus the latitudinal dependence of the measurements cannot be separated from their temporal changes. Successive orbits are separated by $25.4^{\circ}$ longitude. Thus the orbit is similar to that of the single channel SAM (Stratospheric Aerosol Measurement) II instrument, which monitored the polar stratospheric aerosol from 1978 to 1993, and was responsible for the first satellite sightings of polar stratospheric clouds (McCormick et al., 1981, 1982). Solar occultation is employed to measure atmospheric extinction along a ray path at nine wavelengths and like SAGE II, channels are located strategically for the sensing of Rayleigh, $\mathrm{NO}_{2}, \mathrm{O}_{3}, \mathrm{H}_{2} \mathrm{O}$ vapor and aerosol extinction. In this technique (McCormick et al., 1979; McCormick and Wang, 1993) the satellite orbits around the Earth, recording the intensity of solar radiation through the atmosphere each time the Sun comes into view (sunrise event) or disappears from view (sunset event). During a sunrise event, solar intensity is recorded as the tangent height of the ray increases from the Earth's surface to above the top of the atmosphere, and in a sunset event the reverse holds. This technique offers some significant advantages over others. In particular, it is self-calibrating since the exoatmospheric intensity measurement is used to normalize the attenuated intensity measured through the atmosphere, thus eliminating the need for an absolute measurement of solar intensity. This self-calibrating nature is particularly valuable for long-term studies. The geometrical configuration employed in solar occultation also permits high vertical resolution. POAM III, the successor to POAM II, was launched in a similar orbit in March 1998 and is still operational (Lucke et al., 1999; Lumpe et al., 2002). Validation of POAM III aerosol data has been carried out through comparisons with SAGE II and HALOE (Randall et al., 2001).

For both POAM instruments, aerosol extinction data are retrieved at six wavelengths-0.3523, 0.4416, 0.6000, 0.7810, 0.9210 and $1.0600 \mu \mathrm{m}(1.02 \mu \mathrm{m}$ for POAM III). However, these are not completely independent because of the quadratic aerosol parameterization enforced in making the inversion process tractable (see Lumpe et al., 1997). Their transformation to area or volume makes use of the 
Table 1. Coefficients, $a_{i}$, for Extinction Values at POAM III Wavelengths, $\lambda_{i}$ ( $i=$

$1,6)$ Used in the Determination of POAM Aerosol Surface Area and Volume ${ }^{a}$

\begin{tabular}{lcccccc}
\hline Wavelength $(\mu \mathrm{m})$ & $\lambda=0.352$ & $\lambda=0.442$ & $\lambda=0.600$ & $\lambda=0.781$ & $\lambda=0.921$ & $\lambda=1.060$ \\
\hline Surface area & 764 & 531 & 218 & 10 & -65 & -96 \\
Volume & 17 & 31 & 44 & 48 & 46 & 42 \\
\hline
\end{tabular}

${ }^{\mathrm{a}}$ See Equation 2.

Mie expression which relates the scattering and absorption of radiation to the size of the aerosols. In this relationship the aerosols are assumed to be homogeneous, spherical, single-scatterers of radius $r$. The aerosol extinction, $\beta$, at wavelength $\lambda$, is given by:

$$
\beta(\lambda)=\int \pi r^{2} Q_{\text {ext }}(\lambda, r) \frac{d N}{d r} d r=\int \frac{3 Q_{\text {ext }}(\lambda, r)}{4 r} \frac{d V}{d r} d r=\int C(\lambda, r) \frac{d V}{d r} d r
$$

where $Q_{\text {ext }}(\lambda, r)$ is the Mie extinction efficiency, $C(\lambda, r)$ is the (volume) kernel function, $d N / d r$ is the number density of particles per unit radius interval and $d V / d r$ is the volume density of particles per unit radius interval.

In principal component analysis (PCA) the kernel functions, $C(\lambda, r)$, are expanded in terms of a set of orthogonal basis functions. Equation 1 can then be solved for the volume density per unit radius, $d V / d r$, in terms of these eigenvectors and integral properties of the size distribution (total surface-area and volume density) can be simply evaluated from a linear combination of the extinction measurements,

$$
\sum_{i} a_{i} \beta\left(\lambda_{i}\right)
$$

where the $a_{i}$ are coefficients calculated from the Mie kernel and the eigenvalues and eigenvectors of the kernel covariance matrix (Twomey, 1977; Thomason and Poole, 1993; Steele et al., 1999). These coefficients depend upon particle composition-through the refractive index employed in the determination of $C(\lambda, r)$-but once evaluated for a given set of wavelengths, the same coefficients can be applied to every set of extinction measurements to yield surface-area and volume estimates provided that the spatial and temporal variability in the aerosol refractive index is small.

The PCA method has been applied in the determination of surface areas and volumes from SAGE II data (Thomason et al., 1997) and coefficients have been published for both SAGE II and POAM instruments by Steele et al. (1999). These have been used by Randall et al. (2000) and Deshler at al. (2003) in comparisons of aerosol surface-area between SAGE II, POAM II, and in-situ measurements made by Deshler et al. (2003) using an optical particle counter at Laramie, Wyoming. In this paper we use the recommended values from Steele et al. (1999) shown in Table 1.

Errors introduced by the conversion of extinction to surface area and volume are of two types - systematic (errors that are size and composition dependent because of the use of extinction as a proxy); and random (those that arise because of the propagation of experimental errors in the extinction measurements through to the 
area and volume calculations). Steele et al. (1999) estimated the systematics to be up to $50 \%$ for area and $30 \%$ for volume in the case of background aerosol, diminishing for larger particles, and the random errors to be $10-25 \%$. Simulations indicate that the systematic bias introduced by the application of the linear transformation will result in an underestimate of both area and volume for background aerosols. Errors in the extinction measurements themselves are smaller than these, but are highly wavelength-dependent.

The vertical resolution of the POAM instruments is approximately $1 \mathrm{~km}$. Thus extinction measurements, surface-area densities, and volume densities presented herein represent the average over a $1-\mathrm{km}$ altitude interval.

In this paper we present a climatology of the polar aerosol between 1993 and 2003 derived from the satellite data of POAM II and POAM III. For POAM III we use the Version 6 data set, while for the POAM III the Version 3 data have been used. We will examine the residual stratospheric aerosol decay after Pinatubo, the evolution of the stratospheric aerosol over a 10-year period, and its seasonal variation.

\section{DECAY OF PINATUBO AEROSOL}

The eruption of Mt. Pinatubo in June 1991 injected vast quantities of dust, ash and $\mathrm{SO}_{2}$ into the atmosphere. As much as 30 terragrams of particulate material are estimated to have been released into the atmosphere and some reached up to 30 $\mathrm{km}$ into the stratosphere (McCormick et al., 1995) together with an estimated $20 \mathrm{Mt}$ of $\mathrm{SO}_{2}$ (Bluth et al., 1992; Lambert et al., 1997). There was a resulting increase in the optical depth of the tropical stratosphere at 1- $\mu \mathrm{m}$ of some two orders of magnitude over background values (McCormick and Veiga, 1992). (Stratospheric aerosols are formed by nucleation of sulfuric acid and water vapors onto pre-existing particles to form tiny droplets with a composition of $\sim 75 \%$ sulfuric acid, by weight, in the stratosphere (Hamill et al., 1977). This process starts with the conversion of $\mathrm{SO}_{2}$ to $\mathrm{H}_{2} \mathrm{SO}_{4}$ via a series of chemical reactions initiated by the hydroxyl radical, $\mathrm{OH}$. The intermediate radical, $\mathrm{HSO}_{3}$ reacts very quickly with $\mathrm{O}_{2}$, and one of the products, $\mathrm{SO}_{3}$, reacts almost immediately with $\mathrm{H}_{2} \mathrm{O}$ in the atmosphere to produce the sulfuric acid vapor.)

The spatial and temporal evolution of this stratospheric aerosol layer have been well-documented by satellite instruments and by the SAGE II instrument in particular (Lambert et al., 1993, 1997; Thomason et al., 1997; Bauman et al., 2003b). Because the eruption occurred in the tropics (in the Phillipines at $15^{\circ} \mathrm{N}, 121^{\circ} \mathrm{E}$ ), the influence on the stratospheric aerosol was greatest in this region, but the cloud gradually spread throughout the globe over the ensuing weeks and months. The POAM II instrument was not launched until the latter part of 1993. By this time the aerosol was completely dispersed and much of it had been transported from the stratosphere to the troposphere, and deposited on the Earth's surface. This transport, effected by sedimentation, subsidence and tropopause folding, reduced the stratospheric aerosol mass loading from about $30 \mathrm{Tg}$ to $5 \mathrm{Tg}$ by the end of 1993 (McCormick et al., 1995). But even then, and at the high latitudes of the POAM measurements, the influence of this volcanic eruption is the dominant feature of the first three years of the POAM aerosol data. 
A

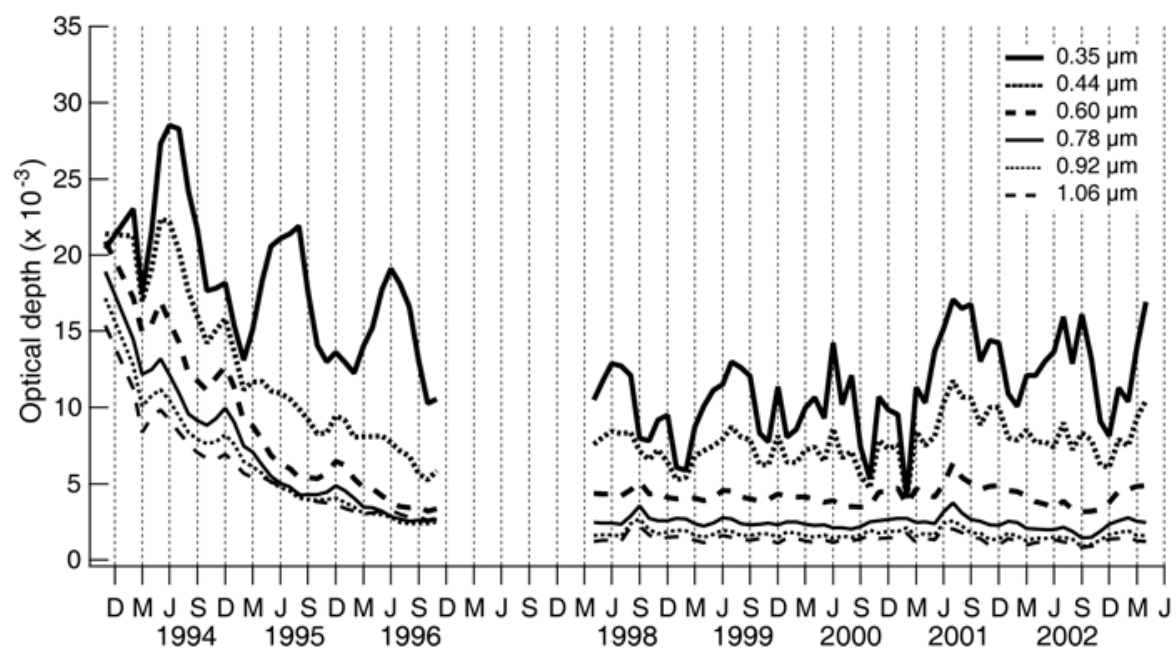

B

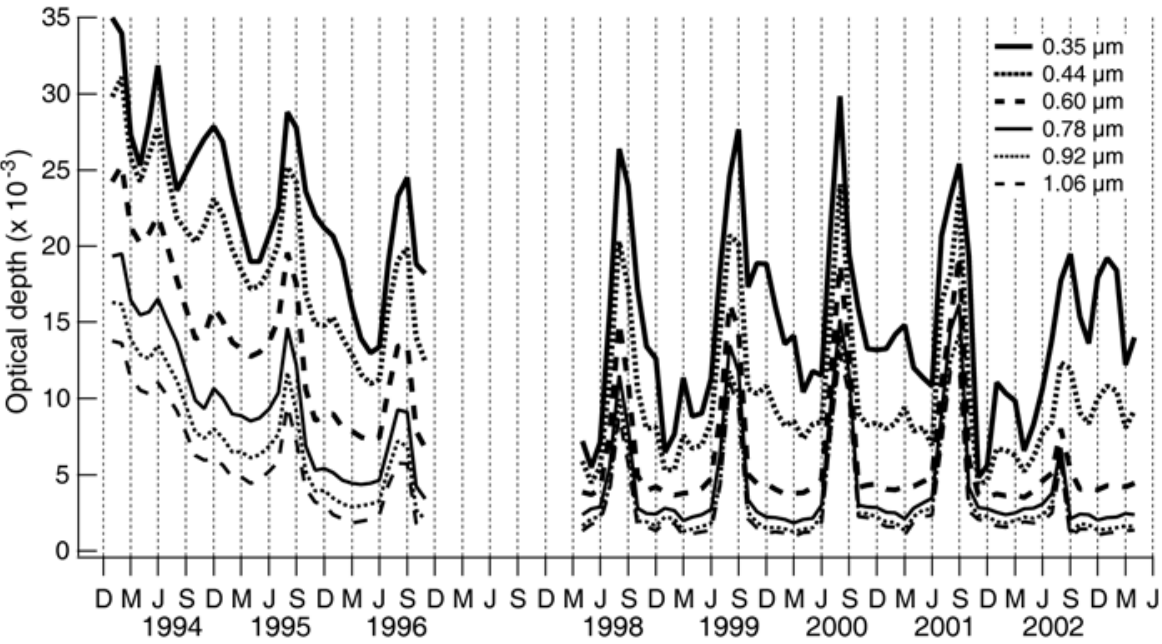

Fig. 1. Stratospheric aerosol optical depth between 12 and $30 \mathrm{~km}$ at six wavelengths as measured by POAM II and III, November 1993-April 2003, for (A) Northern Hemisphere and (B) Southern Hemisphere. Data plotted are monthly medians.

Figure 1 shows the stratospheric aerosol optical depths (extinction integrated from 12 to $30 \mathrm{~km}$ ) at six wavelengths as measured by POAM II and III for the two polar regions. Data are binned by month and the median for each month plotted. Employing the median rather than the mean reduces the effect of outliers and of occasional bad data which may have crept unflagged through the filtering process. POAM II data began in September 1993 and continued until the failure of the SPOT-3 satellite in November 1996. POAM III began collecting data 18 months later. Figure 1 clearly shows the decay of the Pinatubo aerosol throughout the lifetime of POAM II followed by a fairly constant optical depth throughout the history of POAM III from 
mid-1998. Note that, although all the measurements are made at high latitudes, there is a seasonal progression in their location such that they are most poleward at the equinoxes and most equatorward at the solstices. On a single day the measurements are spaced approximately $25^{\circ}$ apart in longitude on a latitude circle.

At the start of the data record - the end of 1993-the 1- $\mu$ m optical depth in the Northern Hemisphere polar region is around 0.014, decaying to a value of 0.0025 three years later. At $0.44 \mu \mathrm{m}$ the optical depth is initially around 0.021 and falls to 0.005 by the end of 1996 . For all years the optical depth falls off monotonically with wavelength because of the small size of the particles. The data at the shortest wavelengths show the most variability. Some of this variability is seasonal (discussed later) and some may be artificial because of error in separating the gas and aerosol components of the extinction. The aerosol signal to noise ratio in the shortest wavelength channels is much lower than at the longer wavelengths because of the dominance of the Rayleigh scattering, and $\mathrm{NO}_{2}$ and ozone absorption (Randall et al., 2001). Thus the quality of the aerosol data is better at $1.06 \mu \mathrm{m}$ than at 0.35 or $0.44 \mu \mathrm{m}$. In the southern polar region the decay from Pinatubo is also very apparent in the first three years of the data, but the effect of polar stratospheric clouds (PSCs), which produce a huge peak in extinction at all wavelengths dominates in the austral winter every year. (At $1 \mu \mathrm{m}$ the extinction from a single PSC can be two orders of magnitude or more greater than nominal background values. Over an optical depth column and over a week of data these clouds cause extinction increases of up to a factor of 10 over background values throughout the entire Antarctic winter season [McCormick et al., 1981]). At the end of 1993 the 1 - $\mu$ m optical depth is very similar to that in the Northern Hemisphere-around 0.014, and decays by about an order of magnitude by the end of 1996 . At $0.440 \mu \mathrm{m}$ the optical depth decreases from 0.030 to 0.012 over the same three-year period.

In the northern polar region, the 1- $\mu$ m optical depth varies between 0.001 and 0.002 throughout the POAM III history. At southern high latitudes the variation over the same time period is very similar if the PSC season is excluded. These optical depths are consistent with the polar measurements taken by the SAM II satellite in 1978 and 1979, its first year of operation (McCormick et al., 1981).

The availability of multiwavelength extinction data permits the calculation of bulk properties by a variety of methods as outlined above. Profiles of volume and area are computed from the extinction profiles using the coefficients of Table 1 and integrated from 12 to $30 \mathrm{~km}$ to yield integrated total aerosol volume and surfacearea densities. Figure 2 shows the monthly medians of these for the high-latitudes of both hemispheres. Superimposed on the data are fits of $y=y_{0} \exp (-\kappa t)$ for the POAM II data from 1993 to 1996. At the end of 1993 the column-integrated stratospheric aerosol volume density for the northern polar region is approximately 4.3

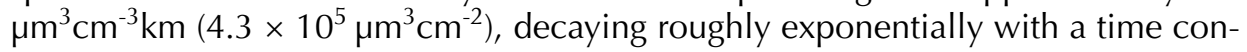
stant $(-1 / \kappa)$ of 1.8 years $(22.2$ months) over the next three years to a background value of $0.87 \mu \mathrm{m}^{3} \mathrm{~cm}^{-3} \mathrm{~km}\left(0.87 \times 10^{5} \mu \mathrm{m}^{3} \mathrm{~cm}^{-2}\right)$ by the end of 1996 . The background level throughout the POAM III years has since averaged about 0.78 $\mu \mathrm{m}^{3} \mathrm{~cm}^{-3} \mathrm{~km}\left(0.78 \times 10^{5} \mu \mathrm{m}^{3} \mathrm{~cm}^{-2}\right)$. In the southern polar region the volume is initially $4.80 \mu \mathrm{m}^{3} \mathrm{~cm}^{-3} \mathrm{~km}\left(4.8 \times 10^{5} \mu \mathrm{m}^{3} \mathrm{~cm}^{-2}\right)$ decaying with a time constant of 2.4 years (28.6 months) over the ensuing three years to a value of $1.30 \mu \mathrm{m}^{3} \mathrm{~cm}^{-3} \mathrm{~km}$ 
A

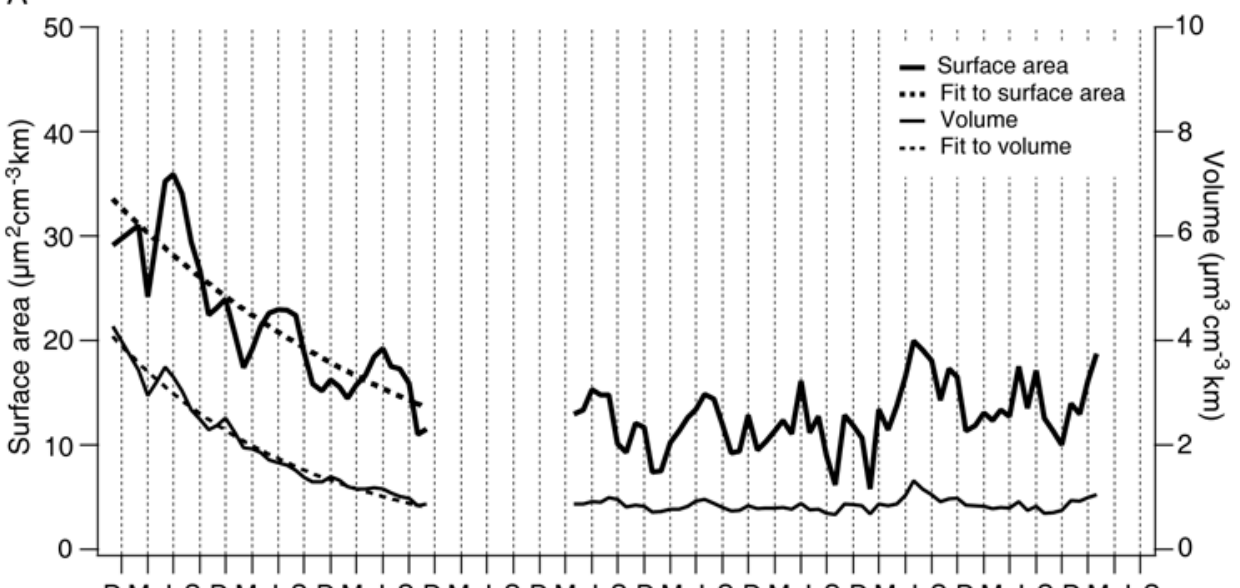

DM J SDM J SDM J SDM J SDM J SDM J SDM J SDM J SDM J SDM J S

$\mathrm{B}$

$19941995 \quad 1996$

$1998 \quad 1999200020012002$

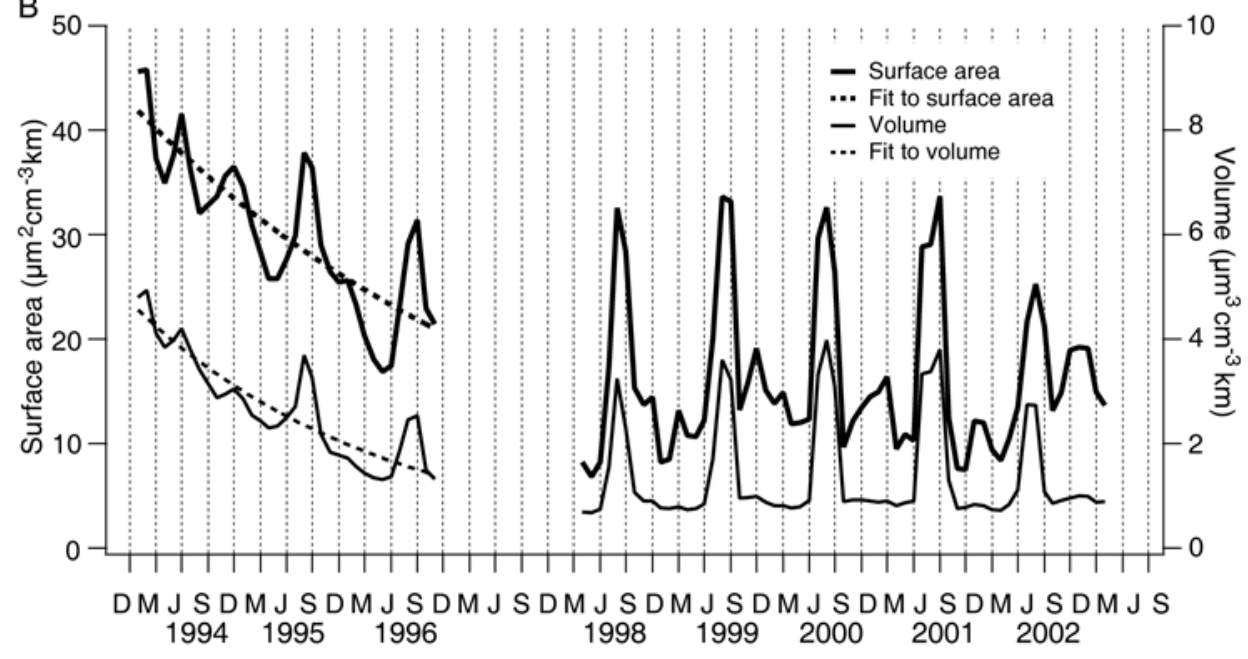

Fig. 2. Integrated aerosol surface-area and volume densities between 12 and $30 \mathrm{~km}$ as measured by POAM II and III, November 1993-April 2003, for (A) Northern Hemisphere and (B) Southern Hemisphere. Data plotted are monthly medians. Dashed lines show the best fits of the data to $y=y_{0} \exp (-k \mathrm{t})$ for the period of POAM II operation, where $t$ is the number of months since the beginning of 1993. (A) Northern Hemisphere: for volume density, $y_{0}=6.7 \mu \mathrm{m}^{3} \mathrm{~cm}^{-3} \mathrm{~km}$ and $k=0.045$ and for surface-area density, $y_{0}=44.25 \mu^{2} \mathrm{~cm}^{-3} \mathrm{~km}, k=0.025$. (B) Southern Hemisphere: for volume density, $y_{0}=7.17$ $\mu \mathrm{m}^{3} \mathrm{~cm}^{-3} \mathrm{~km}$ and $k=0.035$ and for surface-area density, $y_{0}=55.85 \mu \mathrm{m}^{2} \mathrm{~cm}^{-3} \mathrm{~km}, k=0.021$.

$\left(1.3 \times 10^{5} \mu \mathrm{m}^{3} \mathrm{~cm}^{-2}\right)$. By the beginning of the POAM III data three years later, it had

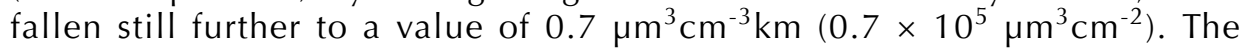
background value since then has averaged around $0.87 \mu \mathrm{m}^{3} \mathrm{~cm}^{-3} \mathrm{~km}\left(0.87 \times 10^{5}\right.$ $\mu \mathrm{m}^{3} \mathrm{~cm}^{-2}$ ), the same as the value obtained for the Northern Hemisphere.

Also shown in Figure 2 are the integrated stratospheric surface-area densities obtained from POAM for the northern and southern polar regions. These exhibit 
much more month-to-month variability than the volume data. Much of the reason for this is the dominance of the contribution of the short-wavelength extinction measurements to the calculation of surface-area density (see coefficients in Table 1). Since the smaller particles have a higher weighting in the total surface area than in the total volume, the weighting of the short wavelength extinction is greater for surface area than volume and hence surface area is more severely affected by noise in these channels. Since these channels have a higher proportion of their total extinction attributed to gases, the signal to noise ratio for aerosol extinction tends to be poorer at shorter wavelengths and hence surface-area retrievals noisier than volume. In the northern polar region the surface-area density at the beginning of 1994 is approximately $30 \mu \mathrm{m}^{2} \mathrm{~cm}^{-3} \mathrm{~km}\left(30 \times 10^{5} \mu \mathrm{m}^{2} \mathrm{~cm}^{-2}\right)$. This falls with a time constant of roughly 3.3 years to a little under a half of that value by the end of 1996. Like aerosol volume density, the surface-area density is also higher in the Southern Hemisphere than the Northern Hemisphere at the end of 1993. At this time, it has

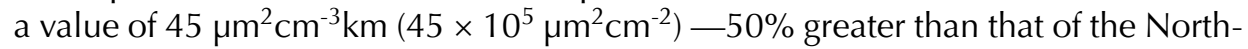
ern Hemisphere. The time constant for decay is slightly higher, 4.0 years, so that

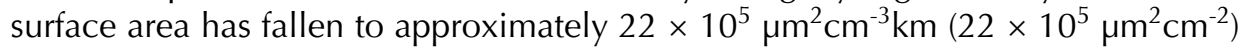
by the end of 1996. These time constants are based on data which have a high variability - which make the starting and ending points of the time interval rather critical in their evaluation. Background values since the end of 1998 are similar for the two hemispheres, but show large variability.

As expected, the volume (or mass) fall-off rate is faster than that of surface area as large particles sediment out of the stratosphere faster than smaller ones, and these make a larger contribution to total aerosol volume (and mass) than to surface area. The e-folding time of the optical depth at the longest $(1.06 \mu \mathrm{m})$ wavelength from POAM II over the shorter period of time between November 1993 and February 1996 was reported to be approximately one year (Randall et al., 1996). Our computed decay constants for volume and surface area are considerably longer than that, and also longer than those of Lambert et al. (1997), who obtained values of 0.94 years (342 days) for mass and 1.20 years (443 days) for surface area from CLAES and ISAMS data between October 1991 and April 1993. In rough agreement with these, Barnes and Hofmann (1997) reported an e-folding time of approximately 1 year for lidar backscatter measurements over Mauna Loa. The 1.06- $\mu \mathrm{m}$ aerosol extinction data are the most stable of the POAM data products. These data show the least seasonal variability and are also least subject to error because of the dominance of aerosol in the total signal. Differences between decay times for surface area (or volume) and $1-\mu \mathrm{m}$ extinction are to be expected as a result of the difference in the size of the particles making the greatest contribution to each. The differences between our data and those of CLAES and ISAMS and the lidar measurements probably arise from a number of factors-most importantly the temporal and geographical differences in the data. Since the CLAES and ISAMS data were obtained immediately after the Pinatubo eruption, the rate of decay is likely to have changed, and have become much less rapid by the time of the POAM II launch 30 months later. During this two-and-a-half-year period the aerosol has become more dispersed and subjected to a range of chemical and dynamical influences. 

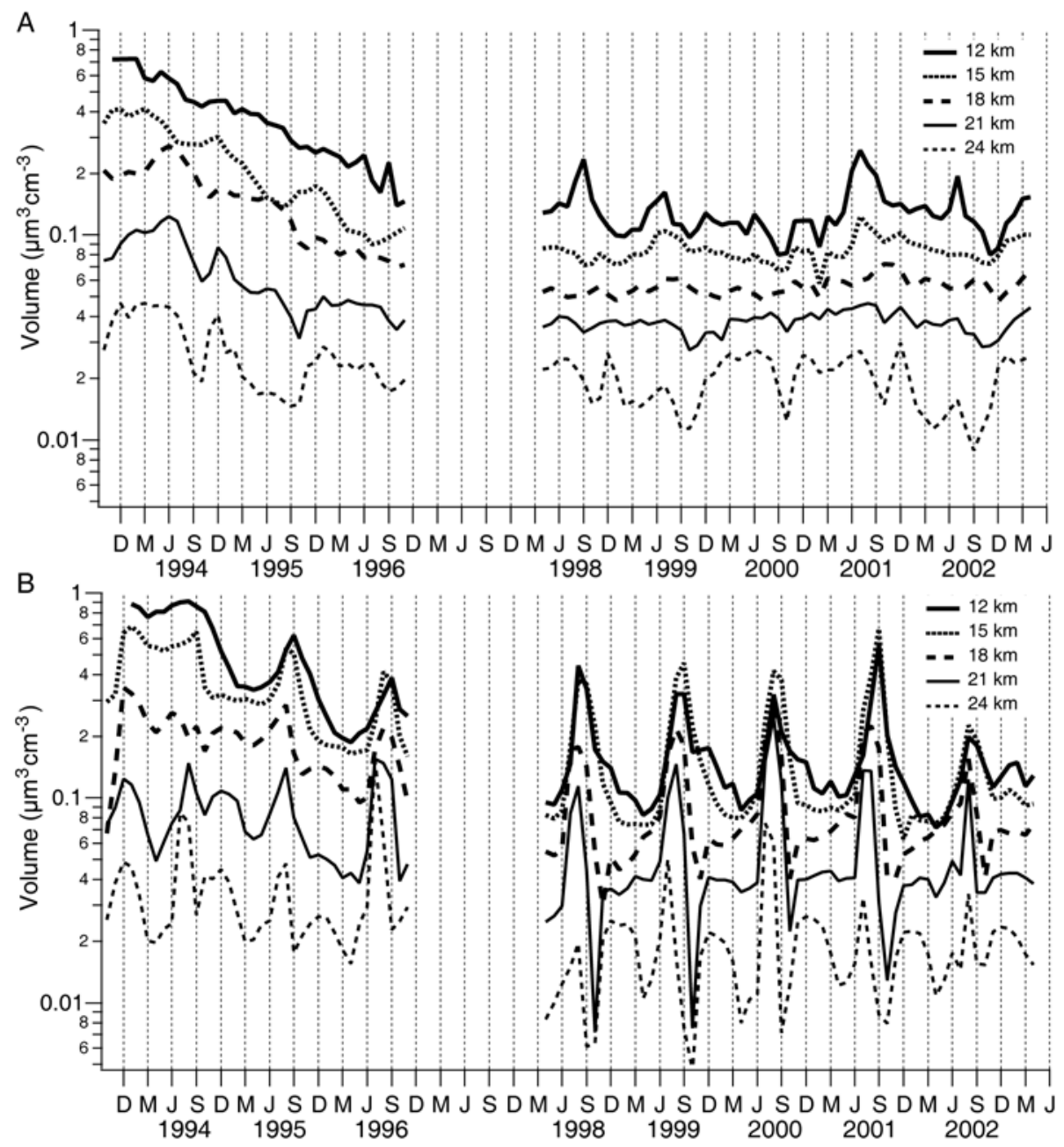

Fig. 3. Stratospheric aerosol volume density from POAM II and III extinction measurements at five altitudes between 12 and $25 \mathrm{~km}$, November 1993-April 2003. Data show monthly medians for (A) Northern Hemisphere region and (B) Southern Hemisphere region.

The evolution of the aerosol layer can also be viewed as a function of altitude. In Figure 3 we show how the polar aerosol volume has changed over the last 10 years at five altitudes in the stratosphere between 12 and $24 \mathrm{~km}$. Figure 3A shows POAM data for northern high latitudes and Figure $3 \mathrm{~B}$ for southern high latitudes. Pinatubo aerosol decay is evident at all altitudes but the decay since the 1991 eruption has progressed further by the beginning of POAM II operation at the higher altitudes than in the lowest part of the stratosphere. Aerosol at higher altitudes was less affected by the injection than at lower altitudes and thus recovered to background 
levels faster. Also the aerosol sedimenting from higher altitudes enhances that at lower altitudes for several years, whereas the higher altitudes do not receive much volume of sedimenting aerosol from above, so background levels are attained at the higher altitudes first. Because of the high month-to-month variability in the data it is difficult to quantify exactly when background equilibrium was attained at each altitude, but the data shown in Figure 3 suggest that it may well have been prior to the end of POAM II operation (at the end of 1996) above $20 \mathrm{~km}$ in the northern high latitudes but two or more years later than this below $20 \mathrm{~km}$. In the Southern Hemisphere the high seasonal variability makes this difference less clear.

Aerosol volume density at $12 \mathrm{~km}$ decays from a value of about $0.7 \mu \mathrm{m}^{3} \mathrm{~cm}^{-3}$ at the end of 1993 to about $0.15 \mu^{3} \mathrm{~cm}^{-3}$ by the end of 1996 in northern high latitudes. The background level at this altitude is $0.13 \mu \mathrm{m}^{3} \mathrm{~cm}^{-3}$. In the southern high latitudes, the volume decays from $0.85 \mu \mathrm{m}^{3} \mathrm{~cm}^{-3}$ to $0.25 \mu^{3} \mathrm{~cm}^{-3}$ over the years of POAM II operation, with a background value of roughly $0.12 \mu \mathrm{m}^{3} \mathrm{~cm}^{-3}$ between 1998 and 2003. The strong influence of PSCs makes the background level difficult to quantify in the southern polar region. Aerosol volume density derived from SAGE measurements (Bauman et al., 2003b) showed that poleward of about $50^{\circ}$ the aerosol layer appears to have recovered to background levels by 1996 above $22 \mathrm{~km}$, but takes increasingly longer as one goes lower in altitude. From Figure 3, there is approximately 15 times as much aerosol at $12 \mathrm{~km}$ as at $24 \mathrm{~km}$ at the start of 1994 . By the time the layer has settled into its background state the difference has diminished to a factor of about six.

\section{SEASONAL VARIATION IN STRATOSPHERIC AEROSOL}

Seasonal aerosol changes are less distinct in POAM II data than in POAM III because of the influence of Pinatubo, but have been summarized by Randall et al. (1996). Here we present POAM III northern (Fig. 4) and southern (Fig. 5) hemisphere monthly median aerosol volume and surface-area densities as a function of altitude since the launch of POAM III. Figure 4 clearly shows at high northern latitudes the late spring-early summer peak in the lower stratospheric aerosol, and Figure 5 the dominance of PSCs at high southern latitudes in winter. Co-located temperature data provided by the United Kingdom Met Office (UKMO) are shown in the bottom panels of Figures 4 and 5. The monthly median latitudes and tropopause heights corresponding to the measurements are shown in Figure 6. Latitudinal and seasonal effects cannot be easily separated because the latitudinal progression of the satellite measurements follows the seasons.

In the Northern Hemisphere data, starting in March each year the aerosol loading in the lower stratosphere, below an altitude of $15 \mathrm{~km}$ or so, starts to increase. It reaches a maximum about three months later, and then falls off again in late summer-fall. This seasonal increase begins at a time when the tropopause is close to its minimum for the year of around $7.5 \mathrm{~km}$ (see Fig. 6) and is starting to rise as the satellite is starting to move to lower latitudes. When the aerosol loading reaches a maximum in June or July the tropopause height is close to its maximum value, a little over $9 \mathrm{~km}$. Between September and December the aerosol loading in the lower stratosphere falls off to its minimum value. This also corresponds to the time 

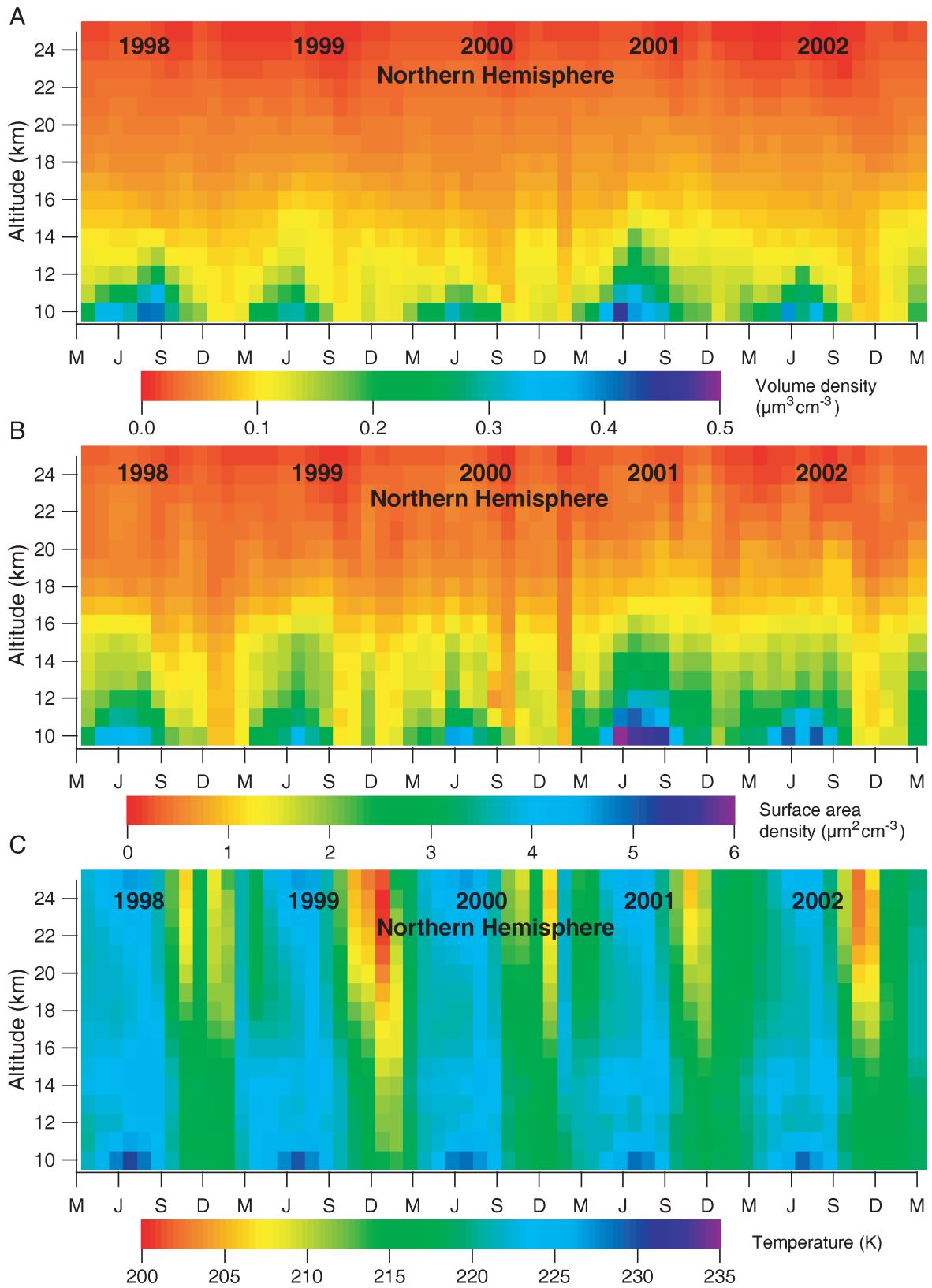

Fig. 4. Monthly median aerosol volume density, surface-area density, and temperature as a function of altitude, March 1998-March 2003. Values shown are from POAM III Northern Hemisphere data.

when the satellite measurements are most poleward. The period of peak aerosol volume and surface-area densities in the lower stratosphere (Figs. 4A and 4B) corresponds to that of warmest temperature in this same region (Fig. 4C). A cool period 

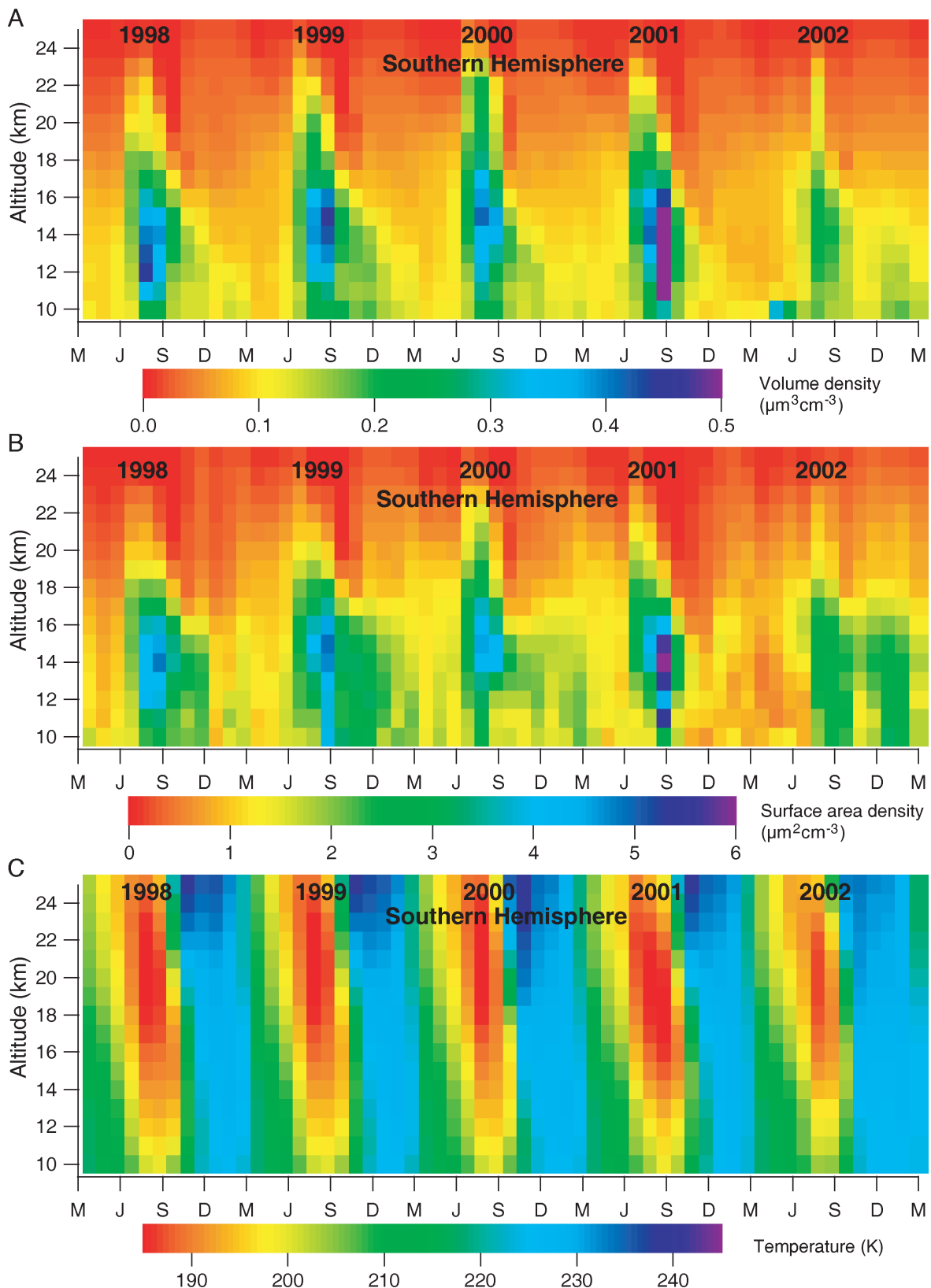

Fig. 5. Monthly median aerosol volume density, surface-area density, and temperature as a function of altitude, March 1998-March 2003. Values shown are from POAM III Southern Hemisphere data.

starting at higher altitudes follows between September and December during which time the aerosol volume and surface area decline to their lowest values of the year. Sometimes the temperature in the mid-stratosphere becomes cold enough for PSCs 


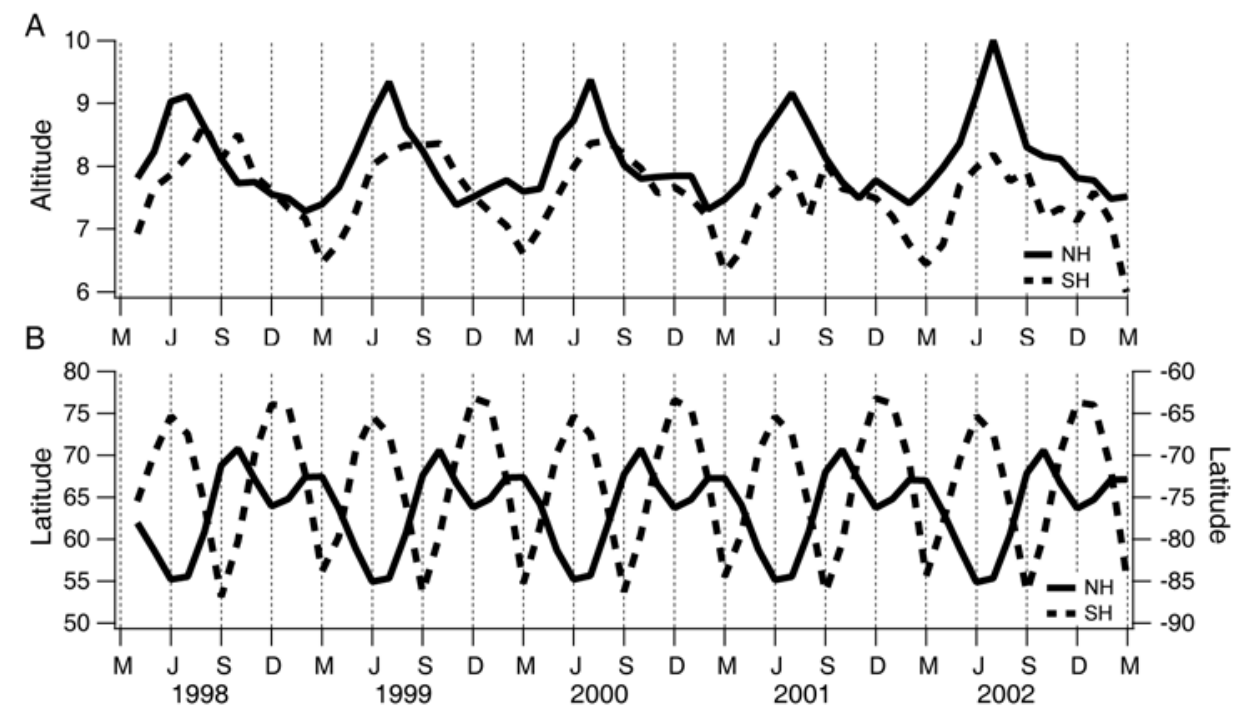

Fig. 6. Monthly median tropopause (A) altitude and (B) latitude of POAM III measurements corresponding to data in Figures 4 and 5.

to form but their influence is not significant enough in the north to be noticeable in the monthly median.

Figure 5 shows the analogous data for the Southern Hemisphere. In this case the aerosol layer is most enhanced not by dynamical forces in spring-summer, but during wintertime because of the presence of polar stratospheric clouds. These clouds are a perennial feature of the Antarctic winter stratosphere, where temperatures commonly fall below $190 \mathrm{~K}$ and the sulfate aerosols absorb nitric acid and water vapors from the stratosphere to form ternary solutions of sulfuric acid, nitric acid and water, or freeze into hydrates of nitric acid or water ices (Toon et al., 1989; Tolbert, 1994). Extinctions as a result of individual clouds are as much as, and even greater than, two orders of magnitude above the background aerosol levels (McCormick et al., 1982; Poole and Pitts, 1994). PSC sightings occur in about 50\% of measured extinction profiles in July each year (Fromm et al., 2003) and their effect is seen at all altitudes from the tropopause up to about $23 \mathrm{~km}$. Monthly median volumes rise by a factor of 4 to 5 at altitudes between 12 and $20 \mathrm{~km}$ (see also Figs. 2 and 3).

The formation of these clouds at progressively lower altitudes as winter deepens can be seen. This is caused by descent of the cold polar air, the sedimentation of PSC particles and the resulting dehydration and denitrification of the air. The appearance of PSCs coincides closely with the onset of cold temperatures in the mid-lower stratosphere (Fig. 5C). Monthly median temperatures below $190 \mathrm{~K}$ are a common feature of the Antarctic winter and the descent of this cold air from altitudes of $20 \mathrm{~km}$ and above in June to $4 \mathrm{~km}$ or so lower two months later, can be seen to drive the lowering of cloud altitude as winter progresses. Each June-July PSCs 
form at altitudes above $20 \mathrm{~km}$, but by the end of winter the altitude of the layer peak has fallen by $4 \mathrm{~km}$ or more. By September-October the stratosphere above $18 \mathrm{~km}$ or so has been cleansed by the descent of the layer. Since measurements progress toward the South Pole between the June solstice and September equinox the air sampled in September and October is most poleward and has undergone the most extensive polar processing. In the summer-fall in the Southern Hemisphere, the aerosol volume and surface-area densities fall to a minimum in the lower stratosphere.

In Figure 7 we show the seasonal average profiles for the Northern and Southern Hemisphere regions sampled by POAM III over the five years since the POAM III launch. Seasonal shifts in the shape of the layer are most pronounced in the southern polar region, where the greatest extremes in temperature are found. In June-July-Aug PSC formation leads to a deep layer of aerosol enhancement between 10 and $22 \mathrm{~km}$ with a clear peak between 13 and $16 \mathrm{~km}$ having an aerosol volume two to three times greater than in the previous three months. This peak has descended and thinned by Spring (Sept-Oct-Nov), producing one with a similar peak magnitude at 11-14 km, but only extending up to an altitude of $16 \mathrm{~km}$ or so. Above this altitude the volume density falls off rapidly until new aerosols are transported into the region, or nucleate and grow. In the Northern Hemisphere there is less season-to-season variability and also less intra-annual variability. There is no distinct layer peak in the volume density, rather it tends to fall off monotonically with altitude.

\section{THE POLAR VORTEX}

The strong winter vortex in the polar regions, and particularly in the Antarctic, plays an important role both in the isolation of the polar air during the winter and in its descent. Figure 8 shows the surface-area density on the $500 \mathrm{~K}$ potential temperature surface (around $20 \mathrm{~km}$ ) in and out of the vortex in the polar regions. Panels show the POAM III data for each year since launch. Red crosses show data inside the polar vortex as defined by Nash et al. (1996) and blue crosses, data outside the vortex. Because of the orbital characteristics of POAM III and the stability of the Antarctic vortex, there are several months of the year when POAM samples exclusively inside the vortex in the southern polar region. However in the northern polar region POAM III samples at lower latitudes (Fig. 6) and the Arctic vortex is much less stable, and breaks up frequently, so POAM III is able to sample both inside and outside the vortex throughout the year.

In the Antarctic there is a clear separation between the characteristics of the air within the vortex and those of the air outside. In mid-winter POAM III is most equatorward (close to $65^{\circ} \mathrm{S}$ ) but completely inside the Antarctic vortex. In most years it will continue to sample only the air trapped within the vortex for the next three months. Surface-area densities are at their highest in early August, and begin to fall in early September as POAM reaches its most poleward extent. At this time the descent of the stratospheric aerosol layer is most pronounced, cloud particles are sedimenting out, and the stratosphere is dehydrating (Nedoluha et al., 2000, 2002). With the exception of the 2002 winter, not until late October or early November 

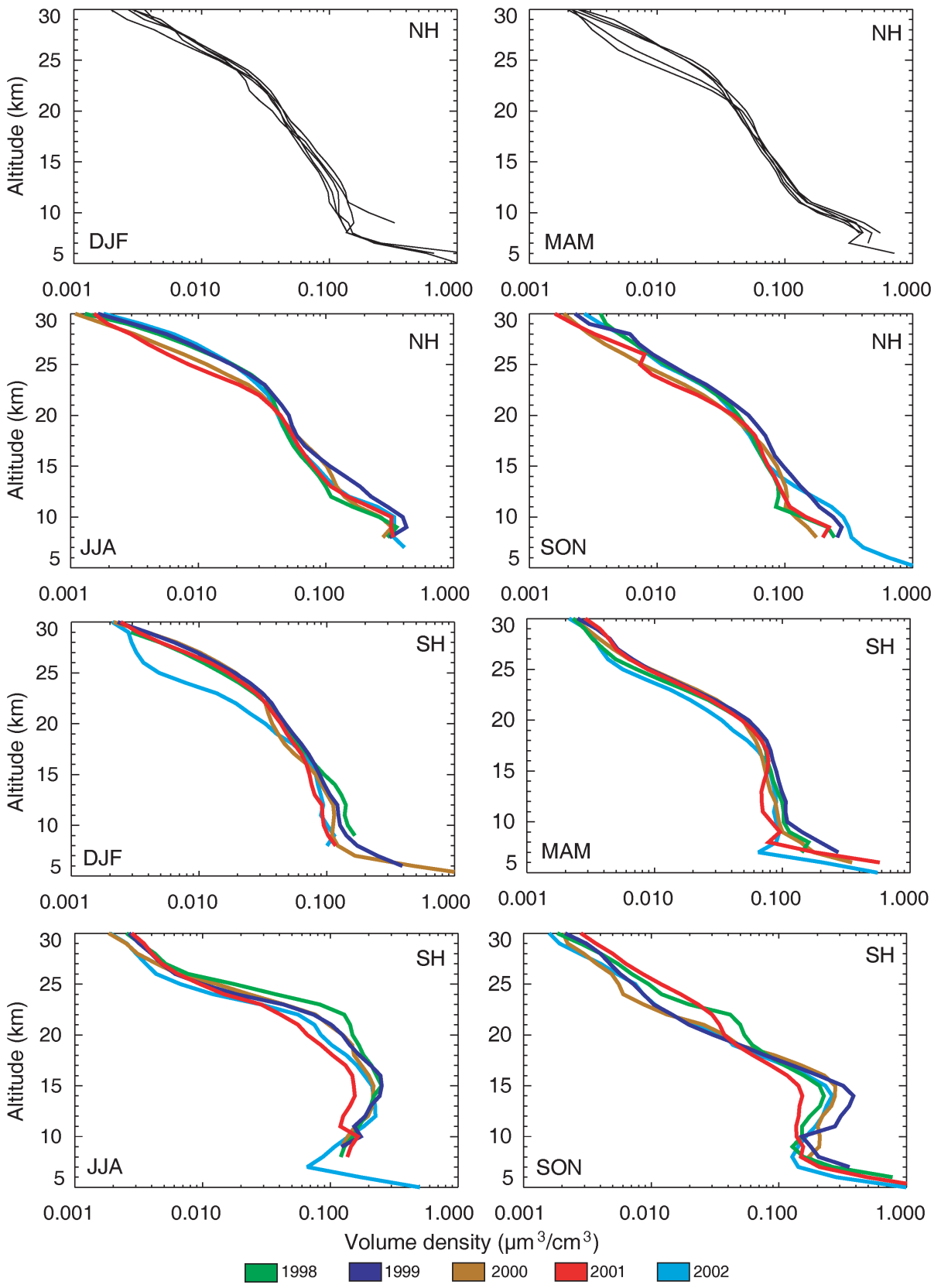

Fig. 7. Seasonal (3-month) average profiles of aerosol volume density for the POAM III Northern Hemisphere $(\mathrm{NH})$ and Southern Hemisphere $(\mathrm{SH})$ data. DJF = December-January-February; MAM = March-April-May; JJA = June-July-August; SON = September-October-November. 

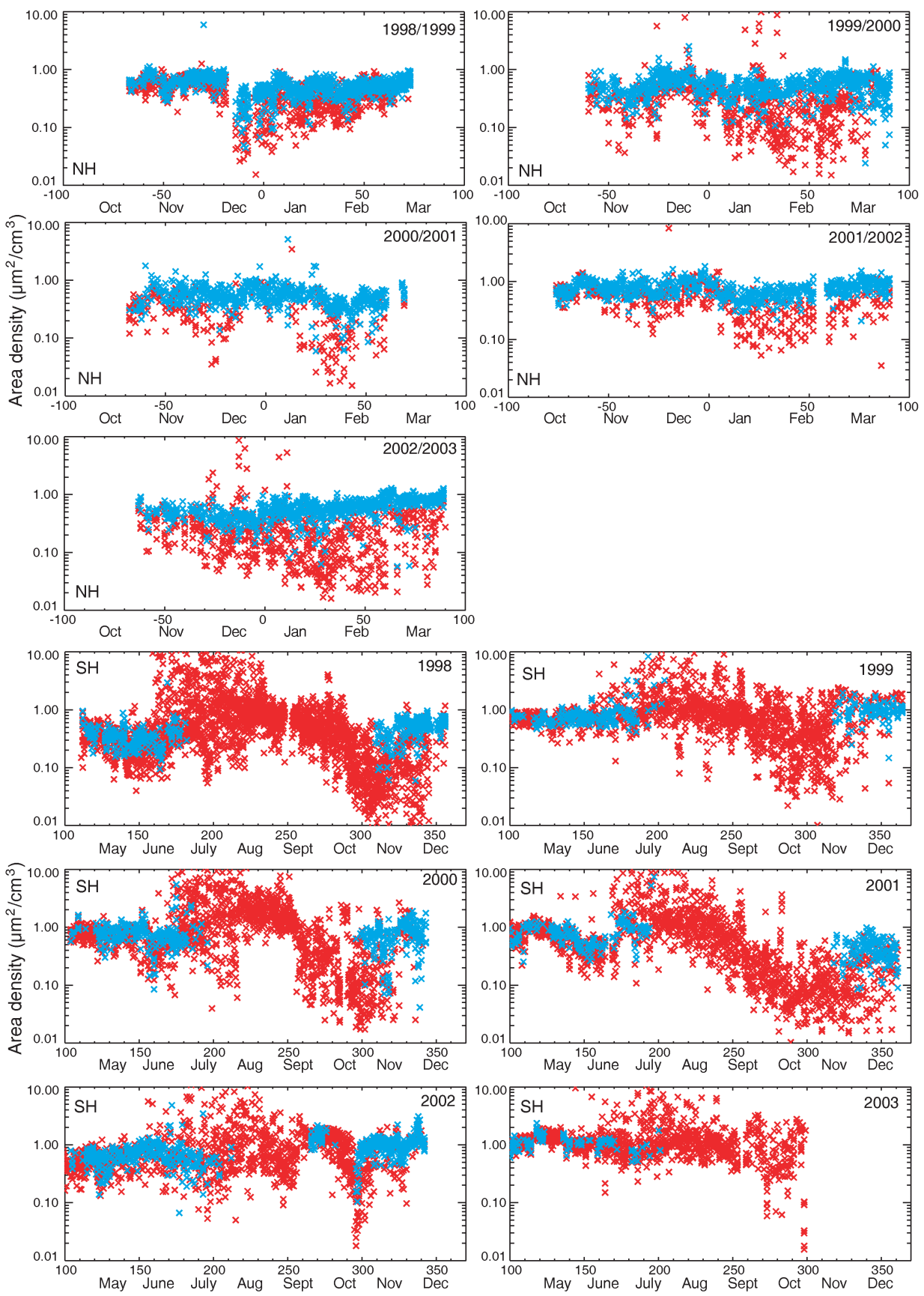

Out of vortex

In vortex

Days Relative to Jan. 1

Fig. 8. Surface-area density on the $500 \mathrm{~K}$ potential temperature surface for each year of POAM III measurements. Data are for the Arctic region. 
does POAM start to sample air both in and out of the vortex as the vortex breaks up and POAM continues to progress to lower latitudes. The clear separation in the aerosol characteristics of these two air masses can be seen. Inside the vortex the air has been chemically processed through heterogeneous reactions on the surfaces of the PSCs, and significantly cleansed at altitudes above $15 \mathrm{~km}$ or so. Eventually it gets replenished as air from lower latitudes is able to penetrate the region, transporting with it aerosols from mid-latitudes. The early break-up and splitting of the vortex in the winter of 2002 (Allen et al., 2003) led to the air inside and outside the vortex having much more similar characteristics in that year. The descent of the air is much less pronounced than in other years and the lack of containment ensures that chemical processing and subsequent ozone depletion is much less severe than normal (Hoppel et al., 2003).

In the northern polar region the winter time behavior is much less dramatic. For nearly all years air from outside the vortex, which comes from the mid-latitudes, has a higher aerosol density than the more poleward air within the vortex and the separation between the two air masses is quite distinct. In including the effects of aerosols in atmospheric models the location of the air with respect to the position of the vortex may thus be more important in determining the surface-area or volume density than the absolute location.

\section{SUMMARY}

A climatology of high-latitude stratospheric aerosols as observed by the POAM II and III instruments between the end of 1993 and mid-2003 has been presented. Optical multiwavelength extinction measurements have been transformed into the physical parameters of surface-area and volume density using principal component analysis, as described in earlier work (Steele et al., 1999). Observations by POAM II clearly show the lingering effects of the Pinatubo eruption on the polar aerosol. It is unclear exactly when the background aerosol level was reached because of both a discontinuity in the instruments and large seasonal effects, but it may well have been in the interval between the two instruments. The exponential decay rates for volume density have been calculated from the POAM II data to be 22.2 months for the northern polar region and 28.6 months for the southern polar region for the years 1993-1996.

The seasonal variation in the aerosol layer shows the strong influence of PSCs in the Antarctic region. The formation of PSCs at lower and lower altitudes, and the descent of the air within the polar vortex is clear as winter progresses. During the winter the seasonal average aerosol volume is enhanced by a factor of two to three at its peak altitude over this region and POAM samples only air within the vortex. The descent and cleansing of the air begins in late August. When Spring arrives and the vortex breaks up POAM samples air from within and outside the vortex and shows a clear distinction between the characteristics of these air masses. The air within the vortex has been cleansed through sedimentation of PSCs and descent. The precipitation of water out of the stratosphere, carried out by falling PSCs has reduced the water vapor available for aerosol renewal in Spring after the PSCs have disappeared (Nedohula et al., 2000). Rehydration starts to take place from 
mid-November to December as air from outside the vortex mixes in, and permits the growth of new aerosols. At northern high latitudes there is also a clear difference between the aerosol loading of air contained within the vortex and that outside, that within the vortex revealing a significantly lower aerosol loading.

The POAM extinction, surface-area, and volume density data are publicly available through the POAM Web site (http://wvms.nrl.navy.mil/POAM/poam.html).

Acknowledgments: The authors would like to acknowledge Cora Randall for her extensive work on validating and interpreting POAM aerosol data, and Mike Fromm and Karl Hoppel for their help in processing and interpreting the POAM data. HMS would like to thank Annmarie Eldering at JPL and Mike Newchurch at the University of Alabama for their support and assistance.

\section{REFERENCES}

Allen, D. R., Bevilacqua, R. M., Nedoluha, G. E., Randall, C. E., and Manney, G. L. (2003) Unusual stratospheric transport and mixing during the 2002 Antarctic winter. Geophysical Research Letters, Vol. 30, 1599, doi:10.1029/ 2003 GL017117.

Barnes, J. E. and Hofmann, D. J. (1997) Lidar measurements of stratospheric aerosol over Mauna Loa. Geophysical Research Letters, Vol. 24, 1923-1926.

Bauman, J. J., Russell, P. B., Geller, M. A., and Hamill, P. (2003a) A stratospheric aerosol climatology from SAGE II and CLAES measurements: 1. Methodology. Journal of Geophysical Research, Vol. 108, No. D13, 4382, doi:10.1029/ 2002JD002992.

Bauman, J. J., Russell, P. B., Geller, M. A., and Hamill, P. (2003b) A stratospheric aerosol climatology from SAGE II and CLAES measurements: 2. Results and comparisons, 1984-1999. Journal of Geophysical Research, Vol. 108, No. D13, 4383, doi:10.1029/2002JD002993.

Baumgardner, D., Dye, J. E., Knollenberg, R. G., and Gandrud, B. W. (1992) Interpretation of measurements made by the forward scattering spectrometer probe (FSSP-300) during the Airborne Arctic Stratospheric Expedition, Journal of Geophysical Research, Vol. 97, 8035-8046.

Bluth, G. J. S., Doiron, S. D., Schnetzier, C. C., Krueger, A. J., and Walter, L. S. (1992) Global tracking of the $\mathrm{SO}_{2}$ clouds from the June, 1991 Mount Pinatubo eruptions. Geophysical Research Letters, Vol 19, 151-154.

Deshler, T., Hofmann, D. J., Johnson, B. J., and Rosier, W. R. (1992) Balloonborne measurements of the Pinatubo aerosol size distribution and volatility at Laramie, Wyoming during the summer of 1991. Geophysical Research Letters, Vol. 19, 199-202.

Deshler, T., Johnson, B. J., and Rosier, W. R. (1993) Balloonborne measurements of Pinatubo aerosol during 1991 and 1992 at $41^{\circ} \mathrm{N}$ : Vertical profiles, size distribution, and volatility. Geophysical Research Letters, Vol. 20, 1435-1438.

Deshler, T., Johnson, B. J., and Rosier, W. R. (1994) Changes in the character of polar stratospheric clouds over Antarctica in 1992 due to the Pinatubo volcanic aerosol. Geophysical Research Letters, Vol. 21, 273-276.

Deshler, T., Hervig, M. E., Hofmann, D. J., Rosen, J. M., and Liley, J. B. (2003) Thirty years of in situ stratospheric aerosol size distribution measurements from 
Laramie, Wyoming $\left(41^{\circ} \mathrm{N}\right)$, using balloon-borne instruments, Journal of Geophysical Research, Vol. 108, 4167, doi:10.1029/2002JD002514.

Dye, J. E., Baumgardner, D., Gandrud, B. W., Kawa, S. R., Kelly, K. K., Loewenstein, M., Ferry, G. V., Chan, K. R., and Gary, B. L. (1992) Particle size distributions in Arctic polar stratospheric clouds, growth and freezing of sulfuric acid droplets, and implications for cloud formation. Journal of Geophysical Research, Vol. 97, 8015-8034.

Fromm, M., Alfred, J., and Pitts, M. (2003) A unified, long-term, high-latitude stratospheric aerosol and cloud database using SAM II, SAGE II, and POAM II/III data: Algorithm description, database definition, and climatology. Journal of Geophysical Research, Vol. 108, doi: 10.1029/2002JD002772.

Glaccum, W., Lucke, R. L., Bevilacqua, R. M., Shettle, E. P., Hornstein, J. S., Chen, J. D., Lumpe, D., Krigman, S. S., Debrestian, D. J., Fromm, M. D., Dalaudier, F., Chassefiere, E., Deniel, C., Randall, C. E., Rusch, D. W., Olivero, J. J., Brogniez, C., Lenoble, J., and Kremer, R. (1996) The polar ozone and aerosol measurement instrument. Journal of Geophysical Research, Vol. 101, 14479-14487.

Grainger R. G., Lambert, A., Rodgers, C. D., Taylor, F. W., and Deshler, T. (1995), Stratospheric aerosol effective radius, surface area and volume estimated from infrared measurements. Journal of Geophysical Research, Vol. 100, 16, 50716518.

Hamill, P., Kiang, C. S., and Cadle, R. D. (1977) The nucleation of $\mathrm{H}_{2} \mathrm{SO}_{4}-\mathrm{H}_{2} \mathrm{O}$ solution aerosol particles in the stratosphere, Journal of the Atmospheric Sciences, Vol. 34, 150-162.

Hervig, M. E. and Deshler, T. (1998) Stratospheric aerosol surface area and volume inferred from HALOE, CLAES, and ILAS measurements. Journal of Geophysical Research, Vol. 103, 25345-25352.

Hoppel, K., Bevilacqua, R. M., Allen, D. R., Nedoluha, G., and Randall, C. E. (2003) POAM III observations of the anomalous 2002 Antarctic ozone hole. Geophysical Research Letters, Vol. 30, 1394, doi:10.1029/2003GL016899.

Lambert, A., Grainger, R. G., Remedios, J. J., Rodgers, C. D., Corney, M., and F. W. Taylor (1993) Measurements of the evolution of the Mt. Pinatubo aerosol cloud by ISAMS. Geophysical Research Letters, Vol. 20, 1287-1290.

Lambert, A., Grainger, R. G., Rodgers, C. D., Taylor, F. W., Mergenthaler, J. L., Kumer, J. B., and Massie, S. T. (1997) Global evolution of the Mt. Pinatubo volcanic aerosols observed by the infrared limb-sounding instruments CLAES and ISAMS on the Upper Atmosphere Research Satellite. Journal of Geophysical Research, Vol. 102, 1495-1512.

Lucke, R. L., Korwan, D., Bevilacqua, R. M., Hornstein, J. S., Shettle, E. P., Chen, D. T., Daehler, M., Lumpe J. D., Fromm, M. D., Debrestian, D., Nef, B., Squire, M., König-Langlo, G., and Davies, J. (1999) The Polar Ozone and Aerosol Measurement (POAM III) Instrument and early validation results. Journal of Geophysical Research, Vol. 104, 18785-18799.

Lumpe, J. D., Bevilacqua, R. M., Hoppel, K. W., Krigman, S. S., Kriebel, D. L., Debrestian, D. J., Randall, C. E., Rusch, D. W., Brogniez, C., Ramananahérisoa, R., Shettle, E. P., Olivera, J. J., Lelnoble, J., and Pruvost, P. (1997) POAM II retrieval 
algorithm and error analysis. Journal of Geophysical Research, Vol. 102, 2359323614.

Lumpe, J. D., Bevilacqua, R. M., Hoppel, K. W., and Randall, C. D. (2002) POAM III retrieval algorithm and error analysis. Journal of Geophysical Research, Vol. 107 (D21), doi: 10.1029/2002JD002137.

Massie, S. T., Deshler, T., Thomas, G. E., Mergenthaler, J. L., and Russell, III, J. M. (1996) Evolution of the infrared properties of the Mount Pinatubo aerosol cloud over Laramie, Wyoming. Journal of Geophysical Research, Vol. 101, 2300723019.

Massie, S. T., Baumgardner, D., and Dye, J. E. (1998) Estimation of polar stratospheric cloud volume and area densities from UARS, SAM II, and POAM II extinction data. Journal of Geophysical Research, Vol. 103, 5773-5783.

McCormick, M. P., Hamill, P., Pepin, T. J., Chu, W. P., Swissler, T. J., and McMaster, L. R. (1979) Satellite studies of the stratospheric aerosol. Bulletin of the American Meteorological Society, Vol. 60, 1038-1046.

McCormick, M. P., Chu, W. P., Grams, G. W., Hamill, P., Herman, B. M., McMaster, L. R., Pepin, T. J., Russell, P. B., Steele, H. M., and Swissler, T. J. (1981) Highlatitude stratospheric aerosols measured by the SAM II satellite system in 1978 and 1979. Science, Vol. 214, 328-331.

McCormick, M. P., Steele, H. M., Hamill, P., Chu, W. P., and Swissler, T. J. (1982) Polar stratospheric cloud sightings by SAM II. Journal of the Atmospheric Sciences, Vol. 39, 1387-1397.

McCormick, M. P. and Wang, P-H. (1993) Satellite occultation measurements of the Earth's atmosphere using SAM II, SAGE and SAGE II. In G. Fiocco and G. Visconti, eds., Diagnostic Tools in Atmospheric Physics. Proceedings of the International School of Physics, June 22-July 2, 1993, Varenna, Italy. Washington, DC: IOS.

McCormick, M. P., Thomason, L. W., and Trepte, C. R. (1995) Atmospheric effects of the Mt. Pinatubo eruption. Nature, Vol. 373, 399-404.

McCormick, M. P. and Veiga, R. E. (1992) SAGE II Measurements of early Pinatubo aerosols. Geophysical Research Letters, Vol. 19, 155-158.

Nash, E. R., Newman, P. A., Rosenfield, J. E., and Schoeberl, M. R. (1996) An objective determination of the polar vortex using Ertel's potential vorticity. Journal of Geophysical Research, Vol. 101, 9471-9478.

Nedoluha, G. E., Bevilacqua, R. M., Hoppel, K. W., Daehler, M., Shettle, E. P., Hornstein, J. H., Fromm, M. D., Lumpe, J. D., and Rosenfield, J. E. (2000), POAM III measurements of dehydration in the Antarctic lower stratosphere. Geophysical Research Letters, Vol. 27, 1683-1686.

Nedoluha, G. E., Bevilacqua, R. M., and Hoppel, K. W. (2002) POAM III measurements of water vapor in the Arctic and Antarctic. Journal of Geophysical Research, doi:10.1029/2001JD001184.

Poole, L. R. and Pitts, M. C. (1994) Polar stratospheric cloud climatology based on Stratospheric Aerosol Measurement II observations from 1978 to 1989. Journal of Geophysical Research, Vol. 99, 13083-13089.

Randall, C. E., Rusch, D. W., Olivera, J. J., Bevilacqua, R. M., Poole, L. R., Lumpe, J. D., Fromm, M. D., Hoppel, K. W., Hornstein, J. S., and Shettle, E. P. (1996) An 
overview of POAM II aerosol measurements at $1.06 \mu \mathrm{m}$. Geophysical Research Letters, Vol. 23, 3195-3198.

Randall, C. E., Bevilacqua, R. M., Lumpe, J. D., Hoppel, K. W., Rusch, D. W., and Shettle, E. P. (2000) Comparison of Polar Ozone and Aerosol Measurement (POAM) II and Stratospheric Aerosol and Gas Experiment (SAGE) II aerosol measurements from 1994 to 1996. Journal of Geophysical Research, Vol. 105, 3929-3942.

Randall, C. E., Bevilacqua, R. M., Lumpe, J. D., and Hoppel, K. W. (2001) Validation of POAM III aerosols: Comparison to SAGE II and HALOE. Journal of Geophysical Research, Vol. 106, 27525-27536.

Steele, H. M., Lumpe, J., Turco, R. P., Bevilacqua, R., and Masie, S. T. (1999) Retrieval of aerosol surface area and volume densities from extinction measurements: Application to POAM II and SAGE II. Journal of Geophysical Research, Vol. 104, 9325-9336.

Thomason, L. W. and Poole, L. R. (1993) Use of stratospheric aerosol properties as diagnostics of Antarctic vortex processes. Journal of Geophysical Research, Vol. 98, 23002-23012.

Thomason, L. W., Poole, L. R., and Deshler, T. (1997) A global climatology of stratospheric aerosol surface area density deduced from Stratospheric Aerosol and Gas Experiment II measurements: 1984-1994. Journal of Geophysical Research, Vol. 102, 8967-8976.

Tolbert, M. A. (1994) Sulfate aerosols and polar stratospheric cloud formation. Science, Vol. 264, 527-528.

Toon, O. B., Turco, R. P., Jordan, J., Goodman, J., and Ferry, G. (1989) Physical processes in polar stratospheric ice clouds. Journal of Geophysical Research, Vol. 94, 11359-11380.

Twomey, S. (1977) Introduction to the Mathematics of Inversion in Remote Sensing and Indirect Measurements. Amsterdam, The Netherlands: Dover. 